\title{
What influences general practitioners' use of child psychiatry services?
}

\author{
Anne Thompson and Maurice Place
}

\begin{abstract}
There are good recwons for improving licison between child poychiatitsts and general practitioners. This study examined whether charecteristics of the GP, potient or sorvice influenced the referral of patients from primary care to the local chlld poychiatiry service. Data collected by seml-structured Interviow from two scomples of general proctitioners who had elther referred frequently or not at all over a two year period folled to show many of the associations found in other studies. Referral behoviour appecers to be a complex phenomenon which moy be influenced by increaing personal contact botween protesslonats.
\end{abstract}

There is a need for a greater collaboration between primary and secondary services to address the psychological health of children. Long-term health planning in the UK aims to reduce emotional and behavioural disorders in children, and there is significant psychiatric morbidity among children seen in primary care. Child psychiatrists still recetve the majority of their referrals from GPs and the referring behaviour of fund-holding practitioners has financial consequences for provider services. This study attempts to determine factors which promote the use of child psychiatry services by general practitioners.

\section{The study}

The Sunderland Child, Adolescent and Family Psychiatry Department has been operating in its present form for 15 years and serves an urban population of approximately 300000 . The department is based in a district general hospital but members of the multidisciplinary team hold regular out-patient sessions in three group practices in the outlying district. Referrals are accepted from health, social service and education professionals with approximately $50 \%$ coming from GPs. Four hundred and fifty referrals were recetved in

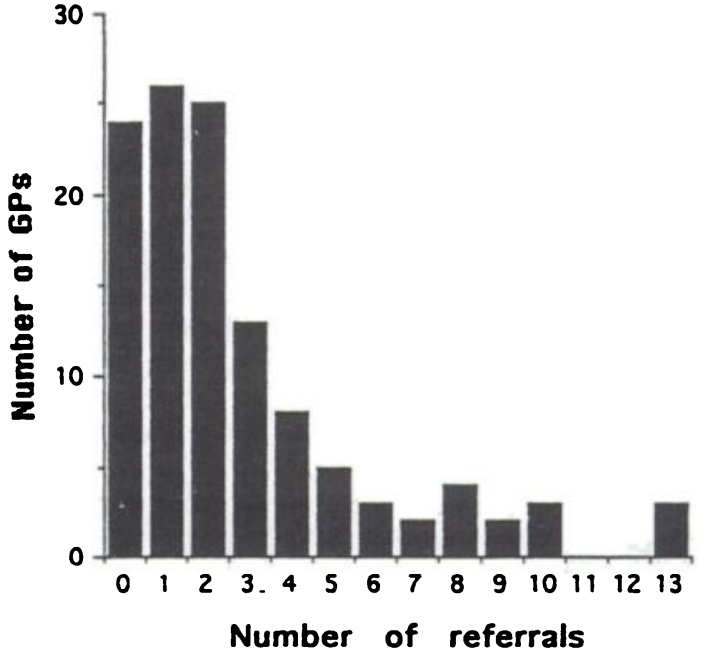

Fig. 1. Number of referrals per GP 1989-1991.

1991, with $18 \%$ of families falling to attend their first appointment and $20 \%$ failing to complete an agreed series of attendances. These figures are similar to those described from other child psychiatry services (Cottrell et al, 1988).

In 1991 there were 143 GPs working in the district, 118 of whom had been there for at least two years. The number of referrals made by these permanent practitioners over that time is shown in Fig. 1 .

The referral pattern approximates to a Poisson distribution as one might predict for a relattvely rare, random event. Although some practitioners had referred many times, a sizeable proportion had not referred to the department at all. We decided to investigate what might explain the difference in practice between these two groups. 
Several well established studies suggest that GPs who refer frequently to adult psychiatric services have particular personal characteristics: they are typically male, older, single-handed practitioners who are interested in psychological issues but lack the practice resources to deal with them. More recent work has found that clinical decisions made while managing psychosocial problems are influenced by GPs' personal attributes, their attitudes to the presenting problem (Dale \& Middleton, 1990) and their reactions to pressure from patients to refer (Armstrong et al, 1991).

Certain family characteristics seem to increase the likelihood of referrals being made to child psychiatry services. Familles of low socio-economic status, children who present with particular symptoms such as anti-soctal behaviour or disorders of elimination and parents who show high levels of distress are all more likely to be referred (Garralda \& Balley, 1988).

We hypothesised that the reasons for the marked differences in the referring behaviour of our local GPs lay in these factors already identified in the literature. We also wanted to look at a number of varlables which our clinical experience suggested might be influenttal. We were particularly interested in whether a GP's referral habits were influenced by knowledge of, and satisfaction with the local service and whether a regular child psychiatry out-patient clinic held in the health centre where the GP worked influenced his or her practice.

The sample for this project comprised two groups of GPs: the 24 GPs working in the district between November 1989 and November 1991 who had not made a referral to the local child psychiatry service over that time (20\% of all GPs in the district) and a comparison group of the 22 GPs who had referred most frequently according to the department's referral statistics $119 \%$ of all GPs made between five and 13 referrals in the two year period).

We approached all doctors in the sample by letter and then telephoned them to ask them to take part in the study. One of us (AT) made a ten minute appointment to gather data on the 13 variables described below using a semistructured interview.

Some intervlews proved to be an opportunity to answer questions about the workings of the department. At the end of the intervlew each GP was given an information sheet about the local service and an invitation to contact staff at the department with any queries in the future.

Data on the practitioners themselves generated nine variables: gender, length of time in practice, number of partners, postgraduate training in paediatrics or child psychiatry, interest in psychological issues, extent of workload involving children, satisfaction with the service, knowledge of the service and preference for referral to regional child and adolescent psychiatry services. Four varlables connected with the practice itself were the socio-economic status of the area around the practice, the distance from the child psychiatry department, whether or not a child psychiatry clinic was held on the premises, and whether the practice was staffed to tackle minor behaviour problems in children.

\section{Findings}

We contacted 46 GPs. Two who were close to retirement and two who claimed never to use the service declined to be seen. Twenty nonreferrers and 22 frequent referrers participated in the study, giving a 91\% response rate. Analysis of the four refusers did not suggest that these practitioners differed from those interviewed in terms of the population they served. We analysed the results using two statistical methods. $\chi^{2}$ tests on cross tabulated results were performed to test for associations between each of the 13 varlables and referring behaviour, and discriminate function analysis was used to determine how satisfactorlly the two groups of non-referring and frequently referring practitioners could be discriminated using all the variables. Only the association between child psychiatry out-patient sessions occurring on the premises and frequent referring behaviour reached statistical significance $(P<0.05)$.

We attempted to gain some measure of the GPs' knowledge of the service by asking them some specific questions. Of the GPs interviewed, $19(45 \%)$ did not know any of the treatment approaches used in the local service. Only two (5\%) of the sample correctly answered three questions about the facilities of the department and the types of referrals we accepted.

When asked about their satisfaction with the service they recetved ten $(24 \%)$ GPs made posittve remarks about the service and 18 
(43\%) had one or more criticisms. The two most common reasons for dissatisfaction were poor communication about the progress of work with families and resources available at the department, and lack of out of hours or immediate appointments.

\section{Comment}

This project looked at the characteristics of non-referrers and frequent referrers to a local child psychiatry service. We suggest that our largely negattve findings reflect limitations in our method and the inability of analyses of this sort to explain varlations in referring behaviour. The relatively small sample size, chance variability and the interviewer not being blind to the referral behaviour of the GPs may have influenced results. In addition, primary care research suggests that the reasons behind differing referral patterns to hospital services may be too complex to be revealed in simple studies of this sort (Willin \& Smith, 1987). A practitioner's decision to refer may be a result of a mixture of attitudes and reasoning which are virtually specific to the individual.

Our only statistically significant finding is that child psychiatry out-patient sessions held in health centres promote referrals to the local child psychiatry service which is in keeping with the findings of Subotsky \& Brown (1990).

As has been shown in other parts of the country, many of the GPs had a scanty knowledge of their local child psychiatry department. We suggest this is an important deficiency because GPs who lack knowledge about the service presumably have difficulty preparing families for referral. This may mean that families form unrealistic expectations about what the referral may achieve which may contribute to the significant drop out rate in child psychiatry clinics (Plunkett, 1984).

Although individual GPs' referral habits tend to remain constant over time, in the nine months following the completion of this study $65 \%$ of the practitioners who had not referred in the previous two years made at least one referral. In line with the findings of Wells \& Faragher (1992) we suggest that personal contact is an effective means of guiding GPs towards makdng more use of child and adolescent psychiatry services.
As we move towards a more consumer orientated style of service provision, GPs' viewpoints will be increasingly important. Child psychiatrists will need to ask what types of case GPs would like to refer and inform them about the types of patient the service currently accepts in order to foster closer links between the GP and the clinic.

\section{Achowiedrements}

We thank all the general practitioners who took part in this study and Drs Patrick Baines and Paul Cavanagh for their valuable contribution to its planning and execution.

\section{References}

Apustrong, D., FRY, J. \& Arustrong, P. (1991) Doctors' perceptions of pressure from patients for referral.Brttish Medical Journal so2, 1186-1188.

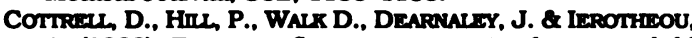
A. (1988). Factors influencing non-attendance at chilld poychiatry out-patient appointments. Brttish Joumal of Psychiatry, 182, 201-204.

DALE, J. \& MiDDLITON, H. (1990) Factors influencing general practitioners' management of poychosocial and physical problems: a study using case vignettes. British Journal of General Practice, 40, 284-288.

Garraida, M. E. \& BAIITY D. (1988) Child and family factors assoclated with referral to child peychiatrists. British Jounal of Psychiatry. 168, 81-89.

Punkstr. J. W. (1984) Parents' treatment expectations and attrition from a child peychiatry service. Joumal of Clinical Prychiatry, 40, 372-377.

SuBotsky, F. \& BRown, R. M. A. (1990) Working alongalde the general practitioner: a child poychiatric clinic in the general practice setting. Child: Care, Health and Development, 16, 189-196.

Weus, P. \& FAR Achiar, B. (1992) Referral rates to a reglonal adolescent peychiatric service: a comparison of vistted and unvisited general practitioners. Health Trends, 24, 53-56.

Wuxw, D. \& Surr, A. (1987) Explaining vartation in general practitioner referrals to hospltal. Famlly Practice, 4 160-169.

*Anne Thompson, Senior Registrar in Child Psychiatry, Fleming Nuffield Unit for Children and Young People, Burdon Terrace, Jesmond, Newcastle upon Tyne NE2 3AE and Maurice Place, Consultant Child Psychiatrist, Department of Child, Adolescent and Family Psychiatry, District General Hospital, Kayll Road, Sunderland SR4 TIP

- Correspondence 